\title{
Chronic, not acute, skin-specific inflammation promotes thrombosis in psoriasis murine models
}

\author{
Jackelyn B. Golden 1,2, Yunmei Wang 3 , Yi Fritz', Doina Diaconu' ${ }^{1}$, Xiufen Zhang 1,3, Sara M. Debanne ${ }^{4}$,
} Daniel I. Simon ${ }^{3,5}$, Thomas S. McCormick ${ }^{1,5}$ and Nicole L. Ward ${ }^{1,5^{*}}$

\begin{abstract}
Background: Psoriasis patients exhibit an increased risk of atherothrombotic events, including myocardial infarction and stroke. Clinical evidence suggests that psoriasis patients with early onset and more severe disease have the highest risk for these co-morbidities, perhaps due to the extent of body surface involvement, subsequent levels of systemic inflammation, or chronicity of disease. We sought to determine whether acute or chronic skin-specific inflammation was sufficient to promote thrombosis.

Methods: We used two experimental mouse models of skin-specific inflammation generated in either an acute (topical Aldara application onto wild-type C57BI/6 mice for 5 days) or chronic (a genetically engineered K5-IL-17C mouse model of psoriasiform skin inflammation) manner. Arterial thrombosis was induced using carotid artery photochemical injury (Rose Bengal-green light laser) and carotid artery diameters were measured post-clot formation. We also examined measures of clot formation including prothrombin (PT) and activated partial thromboplastin time (aPTT). Skin inflammation was examined histologically and we profiled plasma-derived lipids. The number of skindraining lymph-node (SDLN) and splenic derived CD $11 b^{+}$Ly6 $6 C^{\text {high }}$ pro-inflammatory monocytes and CD $11 b^{+} L^{2} 6 G^{+}$ neutrophils was quantified using multi-color flow cytometry.

Results: Mice treated with topical Aldara for 5 days had similar carotid artery thrombotic occlusion times to mice treated with vehicle cream (32.2 \pm 3.0 vs. $31.4 \pm 2.5 \mathrm{~min}, \mathrm{p}=0.97)$; in contrast, K5-IL-17C mice had accelerated occlusion times compared to littermate controls $(15.7 \pm 2.1$ vs. $26.5 \pm 3.5 \mathrm{~min}, \mathrm{p}<0.01)$ while carotid artery diameters were similar between all mice. Acanthosis, a surrogate measure of inflammation, was increased in both Aldara-treated and K5-IL-17C mice compared to their respective controls. Monocytosis, defined as elevated SDLN and/or splenic CD11 b+ Ly6Chigh cells, was significantly increased in both Aldara-treated (SDLN: 3.8-fold, $p=0.02$; spleen: 2.0-fold, $p<0.01$ ) and K5-IL-17C (SDLN: 3.4-fold, $p=0.02$; spleen: 3.5-fold, $p<0.01$ ) animals compared to controls while neutrophilia, defined as elevated SDLN and/or splenic CD $11 \mathrm{~b}^{+} \mathrm{Ly} 6 \mathrm{G}^{+}$cells, was significantly increased in only the chronic K5-IL-17C model (SDLN: 11.6-fold, $p=0.02$; spleen: 11.3-fold, $p<0.01$ ). Plasma-derived lipid levels, PT and aPTT times showed no difference between the Aldara-treated mice or the K5-IL-17C mice and their respective controls.
\end{abstract}

Conclusions: Chronic, but not acute, skin-specific inflammation was associated with faster arterial thrombotic occlusion. Increased numbers of splenic and SDLN monocytes were observed in both acute and chronic skin-specific inflammation, however, increased splenic and SDLN neutrophils were observed only in the chronic skin-specific inflammation model. Understanding the cellular response to skin-specific inflammation may provide insights into the cellular participants mediating the pathophysiology of major adverse cardiovascular events associated with psoriasis.

\footnotetext{
*Correspondence: nlw4@cwru.edu

${ }^{1}$ Department of Dermatology, Case Western Reserve University, 10900

Euclid Ave, Cleveland, OH 44106, USA

Full list of author information is available at the end of the article
} 
Keywords: Psoriasis, Mouse model, Cardiovascular disease, Chronic inflammation, IL-17C, Imiquimod/Aldara, Thrombosis, Monocytosis, Skin, Neutrophils

\section{Background}

Psoriasis vulgaris is a chronic inflammatory skin disease that affects $\sim 2 \%$ of Americans and is characterized by red, scaly, well-demarcated plaques containing activated immune cells [1]. The disease is associated with numerous co-morbidities including psoriatic arthritis [2], diabetes [3], kidney disease [4], and metabolic syndrome [5]. Psoriasis patients also experience increased depression and societal stigmatization [6]. Importantly, individuals with psoriasis have an increased risk of developing and dying of cardiovascular disease (CVD) [7, 8]. Likewise, patients with severe psoriasis have an increased risk of experiencing an adverse cardiovascular event, such as stroke or myocardial infarction (MI) [9], and this occurs independent of other CVD risk factors including age, gender, smoking, diabetes, hypertension, and hyperlipidemia [8]. Causality between psoriasis and CVD is challenging to explore; however, many commonalities exist at the cellular and molecular levels between the two diseases $[10,11]$ and treating psoriasis patients with systemic anti-inflammatory drugs may improve associated CVD outcomes [12].

Recently, we generated and reported a murine model of psoriasis driven by keratinocyte-specific overexpression of Interleukin (IL)-17C, the K5-IL-17C mouse [13]. IL$17 \mathrm{C}$ is an IL-17 family member believed to signal through the receptors IL-17RE/RA [14]. IL-17A and IL-17F are the most highly characterized IL-17 cytokines in the context of psoriasis pathogenesis [15]; however, IL-17C is the most abundant IL-17 isoform expressed in lesional human psoriasis skin [16], and is rapidly responsive to efficacious biologics, implicating a potential pathogenic role in disease [15]. To explore this possibility, K5-IL$17 \mathrm{C}$ mice were genetically engineered to model increased epidermal IL-17C expression [13], and develop a spontaneous skin phenotype similar to human psoriasis that includes the development of disease after birth (i.e. the phenotype begins to appear at $\sim 6-8$ weeks of age), welldemarcated skin lesions with clear gross demarcation between uninvolved and involved skin, an IL-12/23-Th1/ Th17 immune cell phenotype, and improvement of skin pathology upon treatment with TNF- $\alpha$ antagonists [13].

This model system offers a unique opportunity to confirm a pro-thrombotic phenotype resulting from chronic skin-specific inflammation and demonstrate the importance of exposure time to inflammation, or chronicity, to this cardiovascular outcome. Our prior work demonstrated keratinocyte-containment of the transgene using genetic-reporter approaches [17]; thus, we hypothesize that K5-IL-17C mice will develop enhanced thrombosis as a direct result of chronic skin-specific inflammation in the presence of elevated circulating proinflammatory monocytes, similar to that observed in the KC-Tie2 mouse model [17]. Of translational importance, recent work done by our group [18] and others (Dr. Nehal Mehta, NHLBI, personal communication) have identified circulating pro-inflammatory monocytes in psoriasis patients that resemble the increased $C D 11 b^{+}$Ly $6 C^{\text {high }}$ cells observed in the KC-Tie2 model, and which we hypothesize will also be elevated in K5-IL-17C mice, providing a potential link between chronic skin inflammation and the CVD co-morbidities.

Gene-specific contributions to skin inflammation have recently been investigated pre-clinically using acute (5 days) topical application of Aldara (5\% imiquimod; a TLR7/8 agonist) [19]. Controversy over whether this model is appropriate for studying psoriasis pathogenesis has ensued, in part due to the timing of this elicitation, as well as the lack of chronicity associated with human psoriasis. However, this treatment does model some early events in psoriasiform plaque formation, such as increased acanthosis. Both the K5-IL-17C (chronic) model and the Aldara (acute) model result in increased infiltrating dermal $\mathrm{T}$ cells, dendritic cells, and macrophages into lesional tissue [13, 19]. Moreover, similar patterns of elevated pro-inflammatory gene transcripts are observed in lesional skin of both models, including IL-12/23, TNF- $\alpha$, IL-17A, and IL-17C $[13,19,20]$. These unique experimental models provide the opportunity to compare acute vs. chronic skin-specific inflammation and their effects on systemic monocytosis and thrombosis outcomes.

\section{Methods}

Mice

K5-IL-17C mice on a C57Bl/6 background were bred and genotyped as previously described [13] in the Case Western Reserve University (CWRU) animal vivarium. Littermates carrying a single non-expressing transgene (either K5tTA or Tet ${ }^{\mathrm{os}} \mathrm{IL}-17 \mathrm{C}$ ) or no transgenes [herein called C57Bl/6, wildtype (WT)] were used as littermate controls. For Aldara experiments, $\mathrm{C} 57 \mathrm{Bl} / 6$ mice were purchased (Jackson Laboratories, Bar Harbor, ME, USA) and allowed to acclimatize to the CWRU animal vivarium for at least 14 days before beginning topical application of either Aldara or control cream. All mice used 
in the experiments were of similar age (10-16 weeks of age), and both male and female mice were used for all experimental outcomes. Average body weights (in grams) were as follows: WT + vehicle $(21.8 \pm 0.24, \mathrm{n}=21)$, WT + Aldara $(19.8 \pm 0.22, \mathrm{n}=25)$, WT $(22.1 \pm 1.01$, $\mathrm{n}=18)$ and K5-IL-17C $(17.3 \pm 0.40, \mathrm{n}=14)$.

For Aldara experiments, mice were shaved 1 day prior to application of either Aldara or control cream (a petroleum-based cream), which was spread on the dorsal surface of the mouse (5\% Aldara, $3 \mathrm{M}$ Pharmaceuticals; $62.5 \mathrm{mg}$ ) daily for a period of 5 days. As needed, mice were provided with IP saline to supplement fluid loss associated with Aldara treatment, a well-known sideeffect [21]. On day 6, mice underwent the thrombosis protocol outlined below.

Post-hoc statistical analyses examining potential sexdifferences were completed. No differences between sexes were observed for any of our reported outcomes thus male and female animals were grouped together for all experimental analyses.

All animal protocols were approved by the CWRU Institutional Animal Care and Use Committee and conformed to the American Association for Accreditation of Laboratory Animal Care guidelines.

\section{Rose Bengal occlusive thrombosis}

The Rose Bengal thrombosis vascular occlusion assay was completed as previously described [17]. Briefly, male and female K5-IL-17C mice [ $\mathrm{n}=14$; male (5), female (9)] or littermate controls $[\mathrm{n}=21$; male (10), female (11)] or $\mathrm{C} 57 \mathrm{Bl} / 6 \mathrm{WT}$ mice treated with either Aldara $[\mathrm{n}=25$; male (11), female (14)] or control cream $[n=21$; male (10), female (11)] were deeply anesthetized and had their right common carotid artery exposed and monitored by a Doppler flow probe. Animals received a tail-vein injection of Rose Bengal $(50 \mathrm{mg} / \mathrm{kg}$ ) followed by laser illumination of the carotid artery $(540 \mathrm{~nm})$ to initiate thrombosis as described previously [22]. Blood flow was monitored until occlusion occurred, defined as cessation of blood flow for $10 \mathrm{~min}$.

\section{Carotid artery collection post thrombosis}

The right common carotid artery of the mouse undergoing the thrombosis procedure was isolated from surrounding tissues prior to thrombosis induction and two silk sutures were placed under the proximal and distal ends of the carotid artery, respectively. A loose knot that did not disturb blood flow was made on each end of the carotid artery. After blood flow was blocked for $10 \mathrm{~min}$ continuously as a result of thrombosis induction, the two loose knots were tightened to prevent the leakage of the thrombus clot formed and the artery segment was removed.

\section{Tissue processing and measurement of carotid diameters}

The closed-end-carotid artery with thrombus was then fixed in $4 \%$ formaldehyde (Fisher Scientific, Waltham, MA, USA), and subjected to standard histological paraffin embedding and sectioning. Thin $(5 \mu \mathrm{m})$ sections with thrombi were collected sequentially and stained with hematoxylin and eosin (H\&E). Images were acquired using a Zeiss camera (AxioCam MRc5) linked to a microscope (LEICA DM2000). The diameter of the artery (micrometers) was determined by collecting 4 independent measurements distributed evenly across the crosssection of the measured artery and averaged for each animal.

\section{Tissue harvesting and flow cytometry}

Following thrombosis, skin was harvested and processed as described previously for histology and immunohistochemistry [13, 23]. Skin draining axial and inguinal lymph nodes were isolated from a subset of K5-IL-17C transgenic mice and littermate controls $(\mathrm{n}=6$ and $\mathrm{n}=15$; respectively) and Aldara- or control creamtreated $\mathrm{C} 57 \mathrm{Bl} / 6 \mathrm{WT}$ mice $(\mathrm{n}=12$ and $\mathrm{n}=11$; respectively) and were then pooled. Spleens were isolated from a subset of K5-IL-17C transgenic mice and littermate controls and Aldara- or control cream-treated C57Bl/6 WT mice $(n=4-9)$. These tissues were homogenized in serum-free media containing $50 \mu \mathrm{g} / \mathrm{ml}$ DNase I (Sigma, St. Louis, MO) and $2 \mathrm{mg} / \mathrm{ml}$ collagenase D (Roche, Basil). Isolated cells were then pelleted, re-suspended, and filtered $2 \times$ through a $70 \mu \mathrm{m}$ filter in wash buffer containing $5 \%$ FBS. The cells were immediately stained for the cell surface markers Ly6C (Alexa Fluor 700; eBiosciences, San Diego, CA, USA), Ly6G (APC; Abcam, Cambridge, MA, USA), and CD11b (eFlour450; BD, Franklin Lakes, NJ, USA). Flow cytometry data collection was performed using a BD FACS-Aria instrument and analyzed using FlowJo software (Tree Star, Ashland, OR, USA).

See Additional file 1: Figure S1 for gating strategy. For monocyte cell gating, monocytes were first selected on an FSC-A vs. SSC-A plot (S1, panel A). The monocytes were then analyzed for live/dead cell populations using the exclusion dye 7-AAD (S1, panel B). From the live monocyte gate, singlet cells were selected and the doublet events were excluded (S1, panel C). Live singlet cells were then selected for $\mathrm{CD} 11 \mathrm{~b}^{+} \mathrm{Ly} 6 \mathrm{G}^{\text {neg }}$ cells (bottom gate in S1, panel D). From this population, Ly6C was plotted versus SSC-A, and cells that are high on Ly6C and low on SSC-A were considered CD $11 b^{+} \mathrm{Ly} 6 \mathrm{C}^{\text {high }}$, excluding CD11 $\mathrm{b}^{+}$Ly6 $\mathrm{C}^{\text {low }}$ cells and eosinophils (red box in S1, panel E). CD11 b ${ }^{+} \mathrm{Ly}_{6 \mathrm{G}}{ }^{+}$neutrophils were gated as shown in panels $\mathrm{S} 1 \mathrm{~A}, \mathrm{~B}$, and $\mathrm{C}$ and were defined as the population in the top gate with dashed black line in S1, panel D. 


\section{Clotting assays}

\section{Activated partial thromboplastin time}

The activated partial thromboplastin time (aPTT) was performed as described previously [24] with modification. Briefly, $50 \mu \mathrm{l}$ of aPTT reagent (aPTT-SA, Helena Laboratories, Beaumont, Texas, USA) was incubated with $50 \mu \mathrm{l}$ sodium citrate-anticoagulated plasma at $37{ }^{\circ} \mathrm{C}$ for 5 min. Fifty microliters of $30 \mathrm{mM}$ calcium chloride was then added and the time to clot formation was recorded. All samples were tested in duplicate.

\section{Prothrombin time}

The prothrombin time (PT) was performed as described previously [25] with modification. All required reagents were warmed to $37^{\circ} \mathrm{C}$. Fifty microliters of sodium citrateanticoagulated plasma was then added into $100 \mu \mathrm{l}$ of PT reagent (Thromboplastin-LI, Helena Laboratories, Beaumont, Texas, USA) at $37{ }^{\circ} \mathrm{C}$, and the timer was started immediately to record the time to clot formation. Samples were tested in duplicate.

\section{Statistics}

Data analysis and graphs were generated using GraphPad Prism 6 and Microsoft Excel. Results are expressed as mean ( \pm standard error of the mean). Groups were compared using the non-parametric Kruskal-Wallis test. Significance was defined as $\mathrm{p}<0.05$.

\section{Results and discussion}

Aldara was applied to C57Bl/6 WT mice in an area that approximated the surface area of involved dorsal skin on the K5-IL-17C mice (Fig. 1a) and involved skin from both models developed similar increases in acanthosis (epidermal thickness), an often-used surrogate measure of inflammation for murine skin, compared to control cream-treated and littermate controls (Fig. 1b, bottom row compared to top row). We and others have previously reported the increased presence of skin-infiltrating $\mathrm{T}$ cells, myeloid cells, and concomitant increases in proinflammatory cell-derived cytokines, including elevated TNF- $\alpha$, IL-12, IL-23, IL-17A and IL-17C in post-Aldara treated animals and in the chronic K5-IL-17C psoriasiform mouse model $[13,19,20]$. Thus, Aldara, or chronic stimulation of keratinocytes by increased levels of IL-17C leads to cutaneous infiltration of pro-inflammatory cells.

To determine whether the chronicity of skin-specific inflammation affects thrombotic clotting times, we performed the Rose Bengal photochemical carotid artery injury model on the acute inflammatory Aldarainduced model (and control cream-treated mice) as well as the chronic K5-IL-17C mice (and their littermate controls). $\mathrm{C} 57 \mathrm{Bl} / 6 \mathrm{WT}$ mice treated topically with Aldara for 5 days had clotting times similar to $\mathrm{C} 57 \mathrm{Bl} / 6$
WT mice treated with control cream (Fig. 1c, triangles vs. circles; $32.2 \pm 3.0$ vs. $31.4 \pm 2.5 \mathrm{~min}, \mathrm{p}=0.97$; $\mathrm{n}=25, \mathrm{n}=21$, respectively). In contrast, K5-IL-17C mice had significantly reduced times to form occlusive thrombi (enhanced thrombosis) compared to littermate controls (Fig. 1c, diamonds vs. squares; $15.7 \pm 2.1$ vs. $26.5 \pm 3.4 \mathrm{~min}, \mathrm{p}<0.01 ; \mathrm{n}=14, \mathrm{n}=21$, respectively).

To examine potential differences in carotid arteries post-thrombosis, we harvested, sectioned and stained with $H \& E$, the right carotid artery with the thrombus, from representative mice in each experimental group (Fig. 1d). Diameter measurements of carotids did not differ significantly compared to controls in either the acute Aldara model (385 \pm 17.2 , Aldara-treated vs. $401 \pm 18.1$, control cream-treated; $\mathrm{n}=9, \mathrm{n}=8$, respectively) or the chronic IL-17C model $(422 \pm 23.5$, K5-IL-17C vs. $404 \pm 30.6$, littermate controls; $\mathrm{n}=4, \mathrm{n}=7$, respectively) and despite K5-IL-17C mice having the largest carotid artery diameters, they also exhibited the shortest time to occlusive thrombus formation.

To further examine why chronic, and not acute skin inflammation promoted thrombosis, we examined plasma from representative mice to examine ex vivo clotting times and lipid levels. No differences in prothrombin time (PT), an outcome measure that provides insight into influences on the extrinsic coagulation cascade pathway, were observed between Aldara-treated $(17.4 \pm 1.18 \mathrm{~s} ; \mathrm{n}=7)$ and control cream-treated mice $(15.6 \pm 0.94 \mathrm{~s} ; \mathrm{n}=6)$ and between K5-IL-17C mice $(12.8 \pm 0.69 \mathrm{~s} ; \mathrm{n}=6)$ and their littermate controls $(13.8 \pm 0.17 \mathrm{~s} ; \mathrm{n}=6)$. We also examined effects of both acute and chronic skin inflammation on the intrinsic pathway of the coagulation cascade, and measured activated partial thromboplastic time (aPTT). No differences were found between experimental groups or model systems (data not shown). Similarly, examination of plasma lipid levels also failed to demonstrate hyperlipidemia in either model system (data not shown).

These data demonstrate that chronic, but not acute, skin inflammation is associated with faster thrombus formation following activation using the Rose Bengal photochemical injury model of thrombosis and validate our prior observations describing shortened thrombosis times in the KC-Tie2-psoriasiform model in a second skin-specific chronic inflammatory mouse model [17]. Others have recently reported increased endothelial dysfunction following chronic skin-specific overexpression of IL-17A (K14-IL-17A), including increased systolic blood pressure, left ventricular hypertrophy, and reduced survival compared with control animals [26]. Collectively, these findings suggest that chronicity and duration of skin-specific inflammation has the capacity to influence the systemic circulation, distant blood vessels, and promote thrombosis. 
a

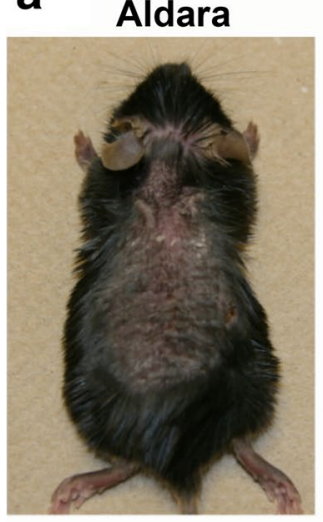

C

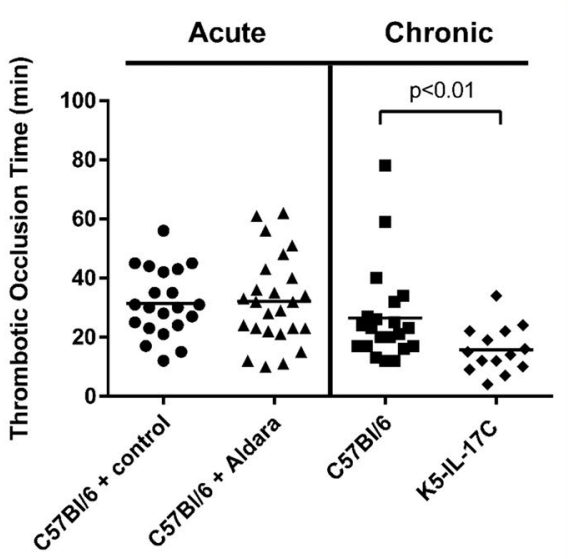

b $_{\text {C57BI/6 + control }}$

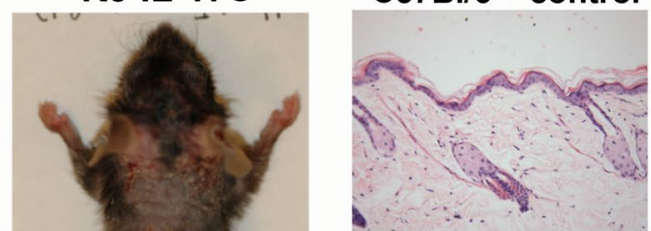

C57Bl/6 + Aldara

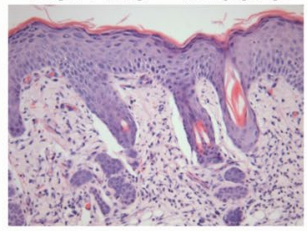

d

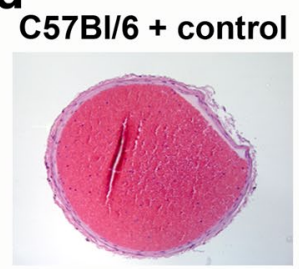

C57Bl/6 + Aldara

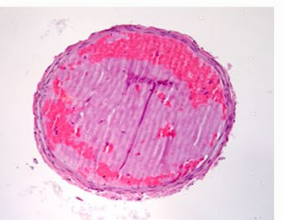

C57BI/6

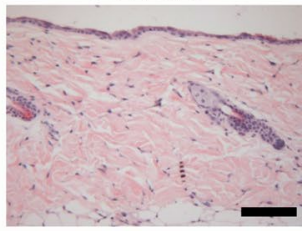

K5-IL-17C

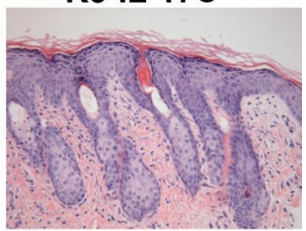

C57BI/6

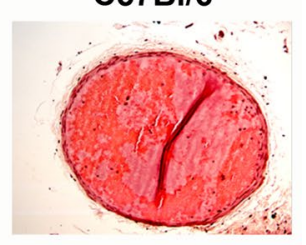

K5-IL-17C

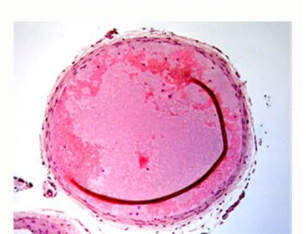

Fig. 1 Chronic, but not acute, skin inflammation promotes shorter arterial clotting times in the Rose Bengal thrombosis assay. a Representative photographs of a C57BI/6 WT mouse treated for 5 days with topical Aldara (left panel) and a K5-IL-17C mouse (right panel). b Representative images of H\&E stained mouse back skin from a C57BI/6 WT mouse treated for 5 days with topical Aldara and a K5-IL-17C mouse demonstrate increases in acanthosis compared to controls. c C57BI/6 WT + Aldara clotting times $(n=25)$ are not different than C57BI/6 WT + control cream $(n=21)$; however K5-IL-17C mice $(n=14)$ have significantly decreased clotting times compared to controls $(n=21), p<0.01$. d Representative photographs of cross sections of carotid arteries post-thrombus formation demonstrate no difference in diameter between the groups. Scale bar in $\mathbf{b}=100 \mu \mathrm{m}$

These preclinical observations are consistent with clinical reports demonstrating that, (1) young psoriasis patients (with moderate-to-severe disease), develop chronic unrelenting systemic inflammation over a sustained period of time and are at highest risk of developing CVD [27]; and (2) psoriasis patients with severe disease, and therefore more significant and prolonged systemic inflammation, have increased risk of thromboembolism [28]. Interestingly, recent epidemiological data suggests that chronicity, or the length of time exposed to persistent inflammation, may play a role in longitudinal increased risk of a myocardial infarction (MI) event, with the more severe psoriasis patients at the greatest risk [29]. Psoriasis patients also had elevated levels of HsCRP (high-sensitivity C-reactive protein), a frequently used measure of systemic inflammation and a surrogate predictor of CVD events [30]. Taken together, these results provide additional evidence that the length of time an individual is exposed to systemic inflammation, such as that derived from inflamed psoriasis skin, appears to increase the risk of developing CVD.

Increased risk of cardiovascular complications has been reported for patients with other chronic organspecific inflammatory diseases, including inflammatory bowel disease and rheumatoid arthritis, where risk of thromboembolism or levels of unstable carotid artery plaque are also significantly elevated (respectively) compared to healthy controls; during a flare in either disease, this risk further increases [31, 32], and then decreases during disease remission [32]. Whether similar increases occur in psoriasis patients during acute flare remains to be examined. 
Inflammation and thrombosis are intertwined in vascular pathology. Observations from pre-clinical and clinical studies indicate that inflammation can beget local thrombosis, and thrombosis can amplify inflammation ([33] and references therein). For example, inflammatory mediators upregulate macrophage tissue factor expression within atherosclerotic plaques, and at the same time, platelets as mediators of thrombosis are critical for the recruitment of inflammatory cells to the vessel wall. Thus, accumulating data linking inflammation and thrombosis support the hypothesis that anti-inflammatory therapies may limit thrombosis and that antithrombotic therapies may reduce vascular inflammation. It is in this context that one must view the contribution of skinspecific inflammation to future adverse cardiovascular events.

Importantly, retrospective meta-analyses suggest some decrease in the incidence of myocardial infarctions in psoriasis patients treated with either TNF inhibitors or anti-IL-12/23 antibody, suggesting that aggressively targeting chronic inflammation and its cellular drivers may reduce life-threatening co-morbidities associated with psoriasis [33, 34]. Our prior findings using the KC-Tie2 mouse model support this, such that reversal of the skin disease, following gene repression, returned thrombosis times to control mouse levels; and reversed aortic root inflammation [17]. Similar improvements in vascular outcomes, including reduced oxidative stress in the heart and blood and attenuation of endothelial dysfunction were reported following TNF- $\alpha$ and IL- 6 neutralization in the K14-IL-17A transgenic model [26]. Support for these preclinical findings are now being observed in prospective studies, such that psoriasis patients treated with systemic biologic anti-inflammatory agents show a lower association with CVD events (cardiovascular death, myocardial infarction, stroke) compared to patients treated with other anti-psoriatic therapies [35].

While there was a significant difference in time to occlusive thrombus formation between the acute and chronic models, we observed no difference in PT, aPTT, or lipid profiles, indicating a potential role for an immune cell mediator in the chronic disease model. Previously, we demonstrated that splenic and SDLN directly correlate with, and reflect, circulating pro-inflammatory $\mathrm{CD}_{11} \mathrm{~b}^{+} \mathrm{Ly}_{6 \mathrm{C}}{ }^{\text {high }}$ monocytes in the chronic, skin-specific KC-Tie2 model [17]. Furthermore, we reported that these cells are increased in $\mathrm{KC}$-Tie 2 mice in the presence of enhanced thrombosis [17] and we recently validated the elevated presence of the human homolog $\left(\mathrm{CD} 14^{+} \mathrm{CD} 16^{++}\right.$intermediate monocytes) in psoriasis patient blood [18]. Finally, increased levels of circulating monocytes have been previously categorized as a risk factor for coronary heart disease [36], indicating that monocytes may participate in the cardiovascular outcomes of the chronic disease model.

To determine if the observed increase in frequency of pro-inflammatory $\mathrm{CD}_{11} \mathrm{~b}^{+} \mathrm{Ly} 6 \mathrm{C}^{\text {high }}$ monocytes may contribute to the promotion of thrombosis, we isolated skin-draining axial and inguinal lymph node (SDLN) cells from a subset of acute Aldara-treated C57Bl/6 WT mice, chronic K5-IL-17C animals, and their relative controls. Using flow cytometry, we measured CD11b, Ly6G, and Ly6C on the surface of SDLN cells (representative image in Additional file 1: Figure S1E, red box). Interestingly, $\mathrm{CD}_{11 \mathrm{~b}}{ }^{+}$Ly6 $\mathrm{C}^{\text {high }}$ pro-inflammatory monocytes were significantly increased in both the acute (Aldara-treated) and chronic (K5-IL-17C) skin inflammation models compared to their respective controls in both the SDLN (Fig. 2a; $66.6 \pm 4.4$, Aldara-treated vs. $17.4 \pm 2.6$, control-cream treated; $\mathrm{p}=0.02, \mathrm{n}=4, \mathrm{n}=4$; and $74.2 \pm 1.2, \mathrm{~K} 5$-IL-17C vs. $21.6 \pm 2.8$, littermate controls; $\mathrm{p}=0.02, \mathrm{n}=3, \mathrm{n}=6$; respectively) and spleen (Fig. $2 \mathrm{~b} ; 81.7 \pm 1.2$, Aldara-treated vs. $40.9 \pm 4.8$, control-cream treated; $\mathrm{p}<0.01, \mathrm{n}=5$, $\mathrm{n}=5$; and $73.9 \pm 8.7, \mathrm{~K} 5$-IL-17C vs. $21.2 \pm 1.3$ littermate controls; $\mathrm{p}<0.01, \mathrm{n}=4, \mathrm{n}=9$; respectively). These data suggest that $C D 11 b^{+}$Ly6 $C^{\text {high }}$ monocytes accumulate rapidly in draining SDLN and spleen following skin inflammation in both the acute and chronic models. Despite the increase in spleen- and SDLN-CD11b ${ }^{+}$Ly6 $6 C^{\text {high }}$ cells, time to occlusive thrombosis formation failed to change significantly between Aldara-treated and their respective control mice (Fig. 1c), suggesting that acute monocytosis alone is not prothrombotic.

In other chronic illnesses, such as HIV, increased levels of circulating lymphocytes and leukocytes have also been observed and proposed to be responsible for the increased risk of cardiovascular events [37]. However, more important than numerical increases, perhaps, is the functional activation of these monocytes and lymphocytes, as suggested by Funderberg et al. [38], who demonstrate that monocytes can become activated by exposure to oxidized LDL (oxLDL), leading to increased cardiovascular risk. Interestingly, psoriasis patients are dyslipidemic and have increased circulating and plaque oxLDL [39]. Moreover, stimulation of macrophages with psoriasis patient-isolated LDL increases production of IL- 6 and TNF- $\alpha$, and also results in increased monocyte adhesion to human umbilical vein endothelial cells [40]. Thus, increases in oxLDL found in psoriasis patients and oxLDL-mediated effects on lymphocytes may provide further support for how skin-inflammation promotes distant vessel inflammation and atherothrombosis. In the acute Aldara and chronic K5-IL-17C model systems, mice did not develop hyperlipidemia (data not shown), consistent with prior observations in KC-Tie2 mice [17], suggesting that the promotion of thrombosis 


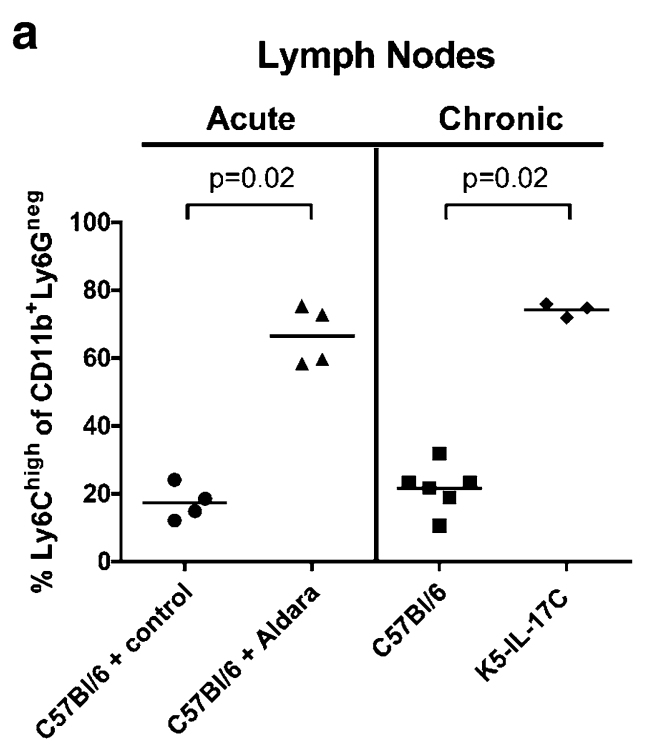

C Lymph Nodes

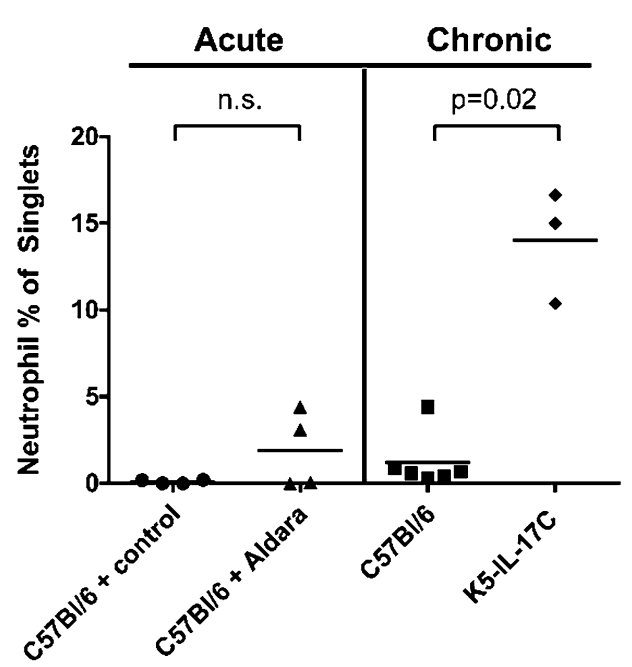

b

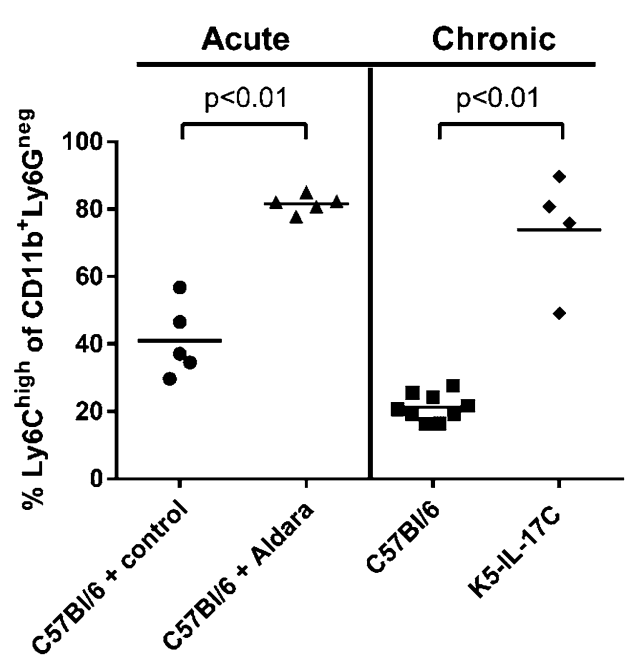

d Spleen

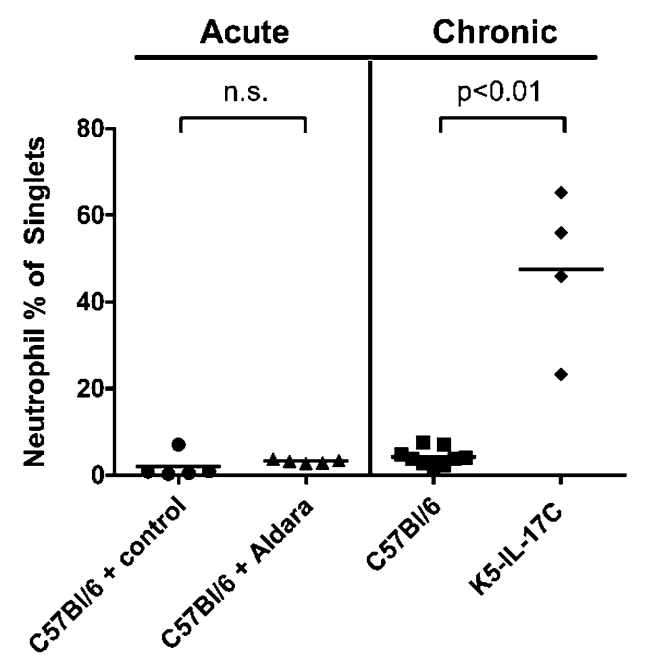

Fig. 2 CD $11 b^{+}$Ly6C high monocytes increase in both Aldara-treated and K5-IL-17C mice whereas CD11 b+ Ly6G ${ }^{+}$neutrophils increase only in K5-IL-17C mice. a Representative flow cytometry dot plots of CD11b and Ly6C surface staining in skin-draining axillary and inguinal lymph nodes $(\mathrm{LN})$. C57BI/6 WT mice treated for 5 days with topical Aldara ( $n=4$ pooled samples) and K5-IL-17C mice ( $n=3$ pooled samples) have increases in skin-draining $L N-C D 11 b^{+} L y 6 C C^{\text {high }}$ cells compared to their respective controls $(n=4$ and $n=6$ pooled samples; $p=0.02$ and $p=0.02$, respectively). Each point represents lymph nodes pooled from 2 to 3 animals. $\mathbf{b}$ Increased splenic-CD 11 b $\mathrm{Ly}_{6 \mathrm{C}}$ high are also observed in Aldara-treated WT mice $(n=5)$ and K5-IL-17C mice $(n=4)$ when compared to their respective controls $(n=5, n=9 ; p<0.01$ and $p<0.01$, respectively). Each point represents a single animal. c Aldara-treated mice have similar levels of SDLN-derived neutrophils $\left(C D 11 b^{+} L y 6 G^{+}\right)$as control-cream treated mice $(n=4$, $\mathrm{n}=4$ ) whereas SDLN CD $11 \mathrm{~b}^{+} \mathrm{Ly}_{6 \mathrm{G}^{+}}$cells are significantly increased in $\mathrm{K} 5-\mathrm{IL}-17 \mathrm{C}$ mice compared to littermate controls $(\mathrm{n}=3$ pooled samples, $n=6$ pooled samples; $p=0.02$, respectively). d Aldara-treated mice have similar levels of splenic CD $11 b^{+}$Ly $_{6 G}{ }^{+}$cells as control-cream treated mice $(n=5, n=5)$ and K5-IL-17C mice have significant increases in splenic CD11 b+Ly6G ${ }^{+}$cells compared to littermate controls $(n=4, n=9$ pooled samples; $\mathrm{p}<0.01$, respectively)

occurs independent of lipid-mediated effects on lymphocytes in these model systems.

Other chronic inflammatory diseases have associated increased cardiovascular risk, and chronic inflammation can extend to inflamed vessels (arteries) that are likely to signal for additional pro-inflammatory leukocytes and lymphocytes [41], leading to increased infiltration of pro-inflammatory cells. This contextual activation of 
both monocytic and endothelial cells may be dependent on the length of exposure to chronic inflammation; such that increased exposure, like that induced in the chronic K5-IL-17C model, but not acute exposure, similar to that elicited by Aldara application, are necessary to compromise endothelial-monocyte (dys)function. Supporting this concept are reports that recent-onset plaque psoriasis patients fail to present with endothelial dysfunction [42] whereas established-plaque psoriasis patients do [43], consistent with the idea that disease duration may lead to the observed dysfunction in chronic patients. Additional observations in an additional preclinical model of psoriasiform skin involvement also demonstrate that overexpression of IL-17A leads to systemic endothelial dysfunction, suggesting that chronic skin inflammation may result in vascular changes indicative of predisposition to eventual cardiovascular dysfunction.

Along with endothelial dysfunction, psoriasis patients also have increases in circulating endothelial cells and microparticles (MPs), which may promote coronary artery disease, acute coronary syndromes and atherothrombosis $[44,45]$. Importantly, these decrease following treatment with anti-TNF- $\alpha$ therapy [44] and could provide mechanistic insight into why TNF- $\alpha$ inhibition reduces risk of MI in psoriasis patients [46].

In addition to MPs and endothelial cells, other cellular mediators of thrombosis such as neutrophils have been previously reported to be elevated in preclinical psoriasis models [26] and human psoriasis patients [47]. Therefore, we also examined $\mathrm{CD}_{11 \mathrm{~b}}{ }^{+} \mathrm{Ly}_{6 \mathrm{G}}{ }^{+}$neutrophils in both spleens and lymph nodes of the chronic and acute psoriasiform models. In the acute Aldara-treated mice, no increases in either SDLN or splenic resident neutrophils were observed compared to control-cream treated mice (Fig. 2c; SDLN: $1.90 \pm 1.10$, Aldara-treated vs. $0.10 \pm 0.06$, littermate controls, $\mathrm{p}=0.37, \mathrm{n}=4, \mathrm{n}=4$; respectively; Fig. 2 d. Spleen: $3.26 \pm 0.17$, Aldara-treated vs. $2.25 \pm 1.62$, littermate controls; $\mathrm{p}=0.28, \mathrm{n}=5$, $\mathrm{n}=4$; respectively). In contrast, K5-IL-17C mice, had elevated neutrophil percentages when compared to littermate controls in both the SDLN (Fig. 2c; $14.0 \pm 1.87$, K5-IL-17C vs. $1.21 \pm 0.65$, littermate controls, $\mathrm{p}=0.02$, $\mathrm{n}=9, \mathrm{n}=4$; respectively) and spleen (Fig. $2 \mathrm{~d} ; 47.6 \pm 9.0$, K5-IL-17C vs. $4.23 \pm 0.66$, littermate controls; $\mathrm{p}<0.01$, $\mathrm{n}=9, \mathrm{n}=4$; respectively).

Elevated monocytes and neutrophils, the activation status of these recruited immune cells, or potentially the micro-milieu the monocytes and neutrophils encounter, may all contribute to the thrombotic potential of the mice. Depletion of neutrophils from an alternative chronic skin inflammation model [26] resulted in decreased reactive oxygen species in peripheral blood, although changes in endothelial dysfunction were not examined. Targeted experiments designed to eliminate monocyte egress from the bone marrow, thus depleting these cells from circulation in psoriasiform mice (i.e., backcross $\mathrm{CCR} 2^{-/-}$and/ or $\mathrm{CCR}^{-1-}$ mice with either KC-Tie2 or KC-IL-17C) should address the necessity and importance of monocytosis for thrombosis alterations. In addition, alternative cellular mediators of inflammation, such as neutrophil extracellular traps (NETs) [48] may play additional, as yet unidentified roles, in the thrombotic process as suggested previously by other investigators, using the Rose Bengal model of thrombosis $[49,50]$. Duration, or chronicity of the skin inflammation, appears to be more correlative with shortened thrombosis times rather than accumulation of pro-inflammatory cellular mediators. However, the duration of the cutaneous cellular response and resultant prolonged exposure to immune cells and derived cytokines may also be a critical factor rather than the appearance of transient pro-inflammatory cells.

\section{Conclusions}

Acute, as well as chronic, skin-specific inflammation promotes the circulation and infiltration of proinflammatory CD $11 b^{+}$Ly $6 C^{\text {high }}$ monocytes into the skin, however, significant changes in neutrophil percentages and occlusive distant vessel thrombosis (following induction by Rose Bengal) occurs only in animals with chronic skin-specific inflammation. Our results provide evidence in an independent second genetic skin-contained mouse model that chronic cutaneous inflammation promotes faster thrombosis following Rose Bengal photoinjury; however our findings also suggest that despite similar levels of skin involvement (body surface area) in acute and chronic models, the length of exposure to skin-elicited inflammation, and elevated cellular participants, such as neutrophils, appear critical to pathogenic outcomes. Further work delineating the cellular and molecular response to psoriasis that promotes inflammation and poor CVD outcomes, at the pre-clinical and clinical levels, are needed to better understand the link between psoriasis and CVD.

\section{Additional file}

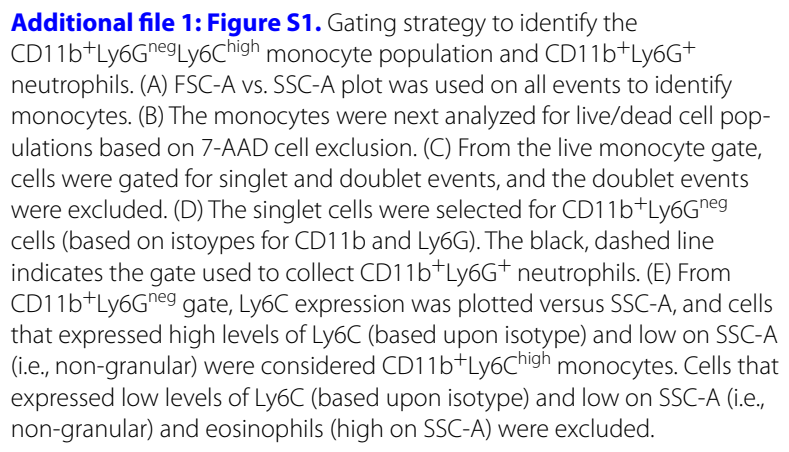




\section{Abbreviations}

aPTT: activated partial thromboplastin time; CVD: cardiovascular disease; hsCRP: high-sensitivity C-Reactive Protein; IL-17C: Interleukin-17C; SDLN: skin-draining lymph node; MI: myocardial infarction; MP: microparticle; NET: neutrophil extracellular trap; oxLDL: oxidized LDL; PT: prothrombin time; TNFa: Tumor necrosis factor alpha; WT: wild type.

\section{Authors' contributions}

JBG carried out and analyzed the monocyte and flow cytometry experiments and drafted the figures and manuscript. DD, YF, and XZ performed the animal husbandry, genotyping, completed the Aldara/control cream application and performed the thrombosis bioassays. SMD performed the statistical analysis. TSM, YW, DIS, and NLW conceived and participated in study design, data collection and analyses, participated in the figure making and wrote and revised the manuscript. All authors read and approved the final manuscript.

\section{Author details}

${ }^{1}$ Department of Dermatology, Case Western Reserve University, 10900 Euclid Ave, Cleveland, $\mathrm{OH} 44106$, USA. ${ }^{2}$ Department of Pathology, Case Western Reserve University, Cleveland, OH, USA. ${ }^{3}$ Harrington Heart and Vascular Institute, University Hospitals Case Medical Center, Case Western Reserve University School of Medicine, Cleveland, OH, USA. ${ }^{4}$ Department of Epidemiology and Biostatistics, Case Western Reserve University, Cleveland, OH, USA. ${ }^{5}$ The Murdough Family Center for Psoriasis, Case Western Reserve University, Cleveland, $\mathrm{OH}$, USA.

\section{Acknowledgements}

This work was supported in part by the The Lozick Discovery Grant, National Psoriasis Foundation (NLW), the National Institutes of Health (P30AR39750 NLW, SMD, TSM; RO1AR063437 NLW, TSM, YW; RO1AR062546, R21AR063852 NLW, TSM; R01AR051498 TSM; R01HL57506 MERIT DIS, YW and T32AR007569 JBG). NLW, TSM, SMD and DIS are members of the Murdough Family Center for Psoriasis. The content is solely the responsibility of the authors and does not necessarily represent the official views of the National Institutes of Health.

\section{Competing interests}

The authors declare that they have no competing interests.

Received: 23 June 2015 Accepted: 23 November 2015

Published online: 16 December 2015

\section{References}

1. Lowes MA, Suarez-Farinas M, Krueger JG. Immunology of psoriasis. Annu Rev Immunol. 2014;32:227-55.

2. Kimball AB, Gladman D, Gelfand JM, Gordon K, Horn EJ, Korman NJ, Korver G, Krueger GG, Strober BE, Lebwohl MG, National Psoriasis F. National Psoriasis Foundation clinical consensus on psoriasis comorbidities and recommendations for screening. J Am Acad Dermatol. 2008;58:1031-42.

3. Armstrong AW, Harskamp CT, Armstrong EJ. Psoriasis and the risk of diabetes mellitus: a systematic review and meta-analysis. JAMA Dermatol. 2013;149:84-91.

4. Wan J, Wang S, Haynes K, Denburg MR, Shin DB, Gelfand JM. Risk of moderate to advanced kidney disease in patients with psoriasis: population based cohort study. BMJ. 2013;347:f5961.

5. Armstrong AW, Harskamp CT, Armstrong EJ. Psoriasis and metabolic syndrome: a systematic review and meta-analysis of observational studies. J Am Acad Dermatol. 2013;68:654-62.

6. Langley RG, Krueger GG, Griffiths CE. Psoriasis: epidemiology, clinical features, and quality of life. Ann Rheum Dis. 2005;64(Suppl 2):ii18-23

\section{(discussion ii24-15)}

7. Gelfand JM, Azfar RS, Mehta NN. Psoriasis and cardiovascular risk: strength in numbers. J Invest Dermatol. 2010;130:919-22.

8. Mehta NN, Azfar RS, Shin DB, Neimann AL, Troxel AB, Gelfand JM. Patients with severe psoriasis are at increased risk of cardiovascular mortality: cohort study using the General Practice Research Database. Eur Heart J. 2010;31:1000-6.
9. Gelfand JM, Dommasch ED, Shin DB, Azfar RS, Kurd SK, Wang X, Troxel $A B$. The risk of stroke in patients with psoriasis. J Invest Dermatol. 2009;129:2411-8.

10. Golden JB, McCormick TS, Ward NL. IL-17 in psoriasis: implications for therapy and cardiovascular co-morbidities. Cytokine. 2013;62:195-201.

11. Shlyankevich J, Mehta NN, Krueger JG, Strober B, Gudjonsson JE, Qureshi AA, Tebbey PW, Kimball AB. Accumulating evidence for the association and shared pathogenic mechanisms between psoriasis and cardiovascular-related comorbidities. Am J Med. 2014;127:1148-53.

12. Ahlehoff O, Skov L, Gislason G, Gniadecki R, Iversen L, Bryld LE, Lasthein S, Lindhardsen J, Kristensen SL, Torp-Pedersen C, Hansen PR. Cardiovascular outcomes and systemic anti-inflammatory drugs in patients with severe psoriasis: 5-year follow-up of a Danish nationwide cohort. J Eur Acad Dermatol Venereol. 2014;29:1128-34.

13. Johnston A, Fritz Y, Dawes SM, Diaconu D, Al-Attar PM, Guzman AM, Chen CS, Fu W, Gudjonsson JE, McCormick TS, Ward NL. Keratinocyte overexpression of IL-17C promotes psoriasiform skin inflammation. J Immunol. 2013;190:2252-62.

14. Bordon Y. Cytokines: IL-17C joins the family firm. Nat Rev Immunol. 2011;11:805.

15. Martin DA, Towne JE, Kricorian G, Klekotka P, Gudjonsson JE, Krueger JG, Russell CB. The emerging role of IL-17 in the pathogenesis of psoriasis: preclinical and clinical findings. J Invest Dermatol. 2013;133:17-26.

16. Johansen C, Usher PA, Kjellerup RB, Lundsgaard D, Iversen L, Kragballe K. Characterization of the interleukin-17 isoforms and receptors in lesional psoriatic skin. Br J Dermatol. 2009;160:319-24.

17. Wang Y, Gao H, Loyd CM, Fu W, Diaconu D, Liu S, Cooper KD, McCormick TS, Simon DI, Ward NL. Chronic skin-specific inflammation promotes vascular inflammation and thrombosis. J Invest Dermatol. 2012;132:2067-75.

18. Golden JB, Groft SG, Squeri MV, Debanne SM, Ward NL, McCormick TS, Cooper KD. Chronic psoriatic skin inflammation leads to increased monocyte adhesion and aggregation. J Immunol. 2015;195:2006-18.

19. van der Fits L, Mourits S, Voerman JS, Kant M, Boon L, Laman JD, Cornelissen F, Mus AM, Florencia E, Prens EP, Lubberts E. Imiquimod-induced psoriasis-like skin inflammation in mice is mediated via the IL-23/IL-17 axis. J Immunol. 2009;182:5836-45.

20. Ha HL, Wang H, Pisitkun P, Kim JC, Tassi I, Tang W, Morasso MI, Udey MC, Siebenlist U. IL-17 drives psoriatic inflammation via distinct, target cellspecific mechanisms. Proc Natl Acad Sci USA. 2014;111:E3422-31.

21. Shah PP, Desai PR, Patel AR, Singh MS. Skin permeating nanogel for the cutaneous co-delivery of two anti-inflammatory drugs. Biomaterials. 2012;33:1607-17.

22. Furie B, Furie BC. Thrombus formation in vivo. J Clin Invest. 2005;115:3355-62.

23. Wolfram JA, Diaconu D, Hatala DA, Rastegar J, Knutsen DA, Lowther A, Askew D, Gilliam AC, McCormick TS, Ward NL. Keratinocyte but not endothelial cell-specific overexpression of Tie2 leads to the development of psoriasis. Am J Pathol. 2009;174:1443-58.

24. Wang Y, Fang C, Gao H, Bilodeau ML, Zhang Z, Croce K, Liu S, Morooka T, Sakuma M, Nakajima K, et al. Platelet-derived S100 family member myeloid-related protein-14 regulates thrombosis. J Clin Invest. 2014;124:2160-71.

25. Mumaw MM, de la Fuente M, Noble DN, Nieman MT. Targeting the anionic region of human protease-activated receptor 4 inhibits platelet aggregation and thrombosis without interfering with hemostasis. J Thromb Haemost. 2014;12:1331-41.

26. Karbach S, Croxford AL, Oelze M, Schuler R, Minwegen D, Wegner J, Koukes L, Yogev N, Nikolaev A, Reissig S, et al. Interleukin 17 drives vascular inflammation, endothelial dysfunction, and arterial hypertension in psoriasis-like skin disease. Arterioscler Thromb Vasc Biol. 2014;34:2658-68.

27. Gelfand JM, Neimann AL, Shin DB, Wang X, Margolis DJ, Troxel AB. Risk of myocardial infarction in patients with psoriasis. JAMA. 2006;296:1735-41.

28. Ahlehoff O, Gislason G, Lamberts M, Folke F, Lindhardsen J, Larsen CT, Torp-Pedersen C, Hansen PR. Risk of thromboembolism and fatal stroke in patients with psoriasis and nonvalvular atrial fibrillation: a Danish nationwide cohort study. J Intern Med. 2014;277:447-55.

29. Koch M, Baurecht H, Ried JS, Rodriguez E, Schlesinger S, Volks N, Gieger C, Ruckert IM, Heinrich L, Willenborg C, et al. Psoriasis and cardiometabolic traits: modest association but distinct genetic architectures. J Invest Dermatol. 2015;135:1283-93. 
30. Liuzzo G, Biasucci LM, Gallimore JR, Grillo RL, Rebuzzi AG, Pepys MB, Maseri A. The prognostic value of C-reactive protein and serum amyloid a protein in severe unstable angina. N Engl J Med. 1994;331:417-24.

31. Grainge MJ, West J, Card TR. Venous thromboembolism during active disease and remission in inflammatory bowel disease: a cohort study. Lancet. 2010;375:657-63.

32. Semb AG, Rollefstad S, Provan SA, Kvien TK, Stranden E, Olsen IC, Hisdal J. Carotid plaque characteristics and disease activity in rheumatoid arthritis. J Rheumatol. 2013:40:359-68.

33. Reich K, Langley RG, Lebwohl M, Szapary P, Guzzo C, Yeilding N, Li S, Hsu MC, Griffiths CE. Cardiovascular safety of ustekinumab in patients with moderate to severe psoriasis: results of integrated analyses of data from phase II and III clinical studies. Br J Dermatol. 2011;164:862-72.

34. Wu JJ, Poon KY, Bebchuk JD. Association between the type and length of tumor necrosis factor inhibitor therapy and myocardial infarction risk in patients with psoriasis. J Drugs Dermatol. 2013;12:899-903.

35. Ahlehoff O, Skov L, Gislason G, Lindhardsen J, Kristensen SL, Iversen L, Lasthein S, Gniadecki R, Dam TN, Torp-Pedersen C, Hansen PR. Cardiovascular disease event rates in patients with severe psoriasis treated with systemic anti-inflammatory drugs: a Danish real-world cohort study. J Intern Med. 2013;273:197-204.

36. Dutta P, Nahrendorf M. Regulation and consequences of monocytosis. Immunol Rev. 2014;262:167-78.

37. Jalbert E, Crawford TQ, D'Antoni ML, Keating SM, Norris PJ, Nakamoto BK, Seto T, Parikh NI, Shikuma CM, Ndhlovu LC, Barbour JD. IL-1Beta enriched monocytes mount massive IL-6 responses to common inflammatory triggers among chronically HIV-1 infected adults on stable anti-retroviral therapy at risk for cardiovascular disease. PLoS One. 2013;8:e75500.

38. Funderburg NT, Jiang Y, Debanne SM, Labbato D, Juchnowski S, Ferrar B, Clagett B, Robinson J, Lederman MM, McComsey GA. Rosuvastatin reduces vascular inflammation and T-cell and monocyte activation in HIV-infected subjects on antiretroviral therapy. J Acquir Immune Defic Syndr. 2015:68:396-404.

39. Mallbris L, Granath F, Hamsten A, Stahle M. Psoriasis is associated with lipid abnormalities at the onset of skin disease. J Am Acad Dermatol. 2006;54:614-21.

40. He L, Qin S, Dang L, Song G, Yao S, Yang N, Li Y. Psoriasis decreases the anti-oxidation and anti-inflammation properties of high-density lipoprotein. Biochim Biophys Acta. 2014;1841:1709-15.
41. Steyers CM 3rd, Miller FJ Jr. Endothelial dysfunction in chronic inflammatory diseases. Int J Mol Sci. 2014;15:11324-49.

42. Mallbris L, Pernow J, Stahle M. Endothelial function and inflammatory activity in patients with recent onset of severe plaque psoriasis. Open Dermatol J. 2008;2:64-8.

43. Shaharyar S, Warraich H, McEvoy JW, Oni E, Ali SS, Karim A, Jamal O, Blaha MJ, Blumenthal RS, Fialkow J, et al. Subclinical cardiovascular disease in plaque psoriasis: association or causal link? Atherosclerosis. 2014:232:72-8.

44. Pelletier F, Garnache-Ottou F, Biichle S, Vivot A, Humbert P, Saas P, Seilles E, Aubin F. Effects of anti-TNF-alpha agents on circulating endothelialderived and platelet-derived microparticles in psoriasis. Exp Dermatol. 2014;23:924-5.

45. Schmidt DE, Manca M, Hoefer IE. Circulating endothelial cells in coronary artery disease and acute coronary syndrome. Trends Cardiovasc Med. 2015;25:578-87.

46. Wu JJ, Poon KY, Channual JC, Shen AY. Association between tumor necrosis factor inhibitor therapy and myocardial infarction risk in patients with psoriasis. Arch Dermatol. 2012;148:1244-50.

47. Naik HB, Natarajan B, Stansky E, Ahlman MA, Teague H, Salahuddin T, Ng Q, Joshi AA, Krishnamoorthy P, Dave J, et al. Severity of psoriasis associates with aortic vascular inflammation detected by FDG PET/CT and neutrophil activation in a prospective observational study. Arterioscler Thromb Vasc Biol. 2015. (Epub ahead of print)

48. Fuchs TA, Brill A, Duerschmied D, Schatzberg D, Monestier M, Myers DD Jr, Wrobleski SK, Wakefield TW, Hartwig JH, Wagner DD. Extracellular DNA traps promote thrombosis. Proc Natl Acad Sci USA. 2010;107:15880-5.

49. Knight JS, Subramanian V, O'Dell AA, Yalavarthi S, Zhao W, Smith CK, Hodgin JB, Thompson PR, Kaplan MJ. Peptidylarginine deiminase inhibition disrupts NET formation and protects against kidney, skin and vascular disease in lupus-prone MRL/Ipr mice. Ann Rheum Dis. 2015;74(12):2199-206

50. Knight JS, Zhao W, Luo W, Subramanian V, O'Dell AA, Yalavarthi S, Hodgin JB, Eitzman DT, Thompson PR, Kaplan MJ. Peptidylarginine deiminase inhibition is immunomodulatory and vasculoprotective in murine lupus. J Clin Invest. 2013;123:2981-93.

\section{Submit your next manuscript to BioMed Central and we will help you at every step:}

- We accept pre-submission inquiries

- Our selector tool helps you to find the most relevant journal

- We provide round the clock customer support

- Convenient online submission

- Thorough peer review

- Inclusion in PubMed and all major indexing services

- Maximum visibility for your research

Submit your manuscript at www.biomedcentral.com/submit

\section{() Biomed Central}

